\title{
Social inclusion, care and belonging of children with spina bifida: perspectives from Uganda'
}

\author{
Femke Bannink \\ Department of Special Needs Education, Ghent University
}

\begin{abstract}
This study presents a situation analysis on daily functioning, caregiving, and inclusion of children with spina bifida in Uganda. 139 children with spina bifida and their families from 4 regions in Uganda participated in this study. Findings show how a complex play of cultural values, globalization and access to biomedical care determines knowledge, and negative attitudes about, and perception of children with spina bifida. Families and private non for profit organisations are the main providers of care of the children. Children with spina bifida had a more negative perception of themselves, were less likely to be in school, and had lower cognitive outcome compared to their siblings. Daily functioning and social inclusion were affected by motor function, incontinence, lack of support for caregivers, low household income, limited resources and knowledge of inclusive teaching, bullying, and inaccessibility of public transport, roads, and buildings. Positive experiences of belonging were found at family and household level and were closely related to the 'ubuntu' concept. When a child belongs, the child has a chance to live, to participate, to become, to be included. To facilitate inclusion, families need to be supported, and negative attitudes and behaviour of community members, teachers, and health workers need to be addressed.
\end{abstract}

Key words: disability, inclusion, spina bifida, Uganda, Africa

\section{Introduction}

In sub-Saharan Africa Disability Studies have largely focused on adults with disabilities and the caregivers of children with disabilities, and have primarily been conducted in South Africa (Curran \& Runswick-Cole, 2014). This study presents a situation analysis on social inclusion, care and belonging of children with spina bifida in Uganda. Spina bifida is a congenital disability, whereby the spinal cord and vertebrae do not form completely and the neural tube fails to develop normally (Northrup \& Volcik, 2000). Most children with spina bifida have some degree of paralysis, which affects mobility as well as bowel and bladder control (Verpoorten \& Buyse, 2008). The majority of children with spina bifida develop hydrocephalus, a condition in which the circulation of cerebrospinal fluid 
in the brain is obstructed, the fluid accumulates, and the head enlarges (International Federation for Spina Bifida and Hydrocephalus, 2014). In Uganda an estimated I,400 children are born with spina bifida annually (Warf, Wright, \& Kulkarni, 20II); about 30\% receive neurosurgery, which is available in 3 locations in the country. Without surgery, most children with spina bifida die. This study focuses on the children who have survived. It describes the bodily experiences and limitations experienced by the children due to reduced functioning on the one hand and poverty, cultural, and social barriers on the other hand. The study was supported by the International Federation for Spina Bifida and Hydrocephalus and Child-Help.

\section{Method}

Between 2011 and 2015 children with spina bifida and their families were selected from the following rehabilitation centers where specialized outreach clinics and rehabilitative care are offered: CURE Children's hospital of Uganda in Mbale, Katalemwa Cheshire Home in Kampala, Gulu Regional Rehabilitation Centre in Gulu, Lira Government Hospital in Lira, and Organised Useful Rehabilitation Services in Mbarara. Semi-structured interviews, observations, and focus groups discussions were held with children, parents, hospital and rehabilitation centre staff, teachers, community members, and local leaders to study knowledge, attitudes, perceptions, access to and use of health and rehabilitation services, and experiences of belonging of children with spina bifida. A set of assessment scales to measure gross and fine motor function, daily functioning (Sparrow, Balla, Cicchetti, \& Doll, 1984), and cognitive outcomes (Beery, Buktenica, \& Beery, 1989; Bangirana, Bangirana, Seggane, Allebeck, et al., 2009; Nampijja, Apule, Lule, Akurut, et al., 2010) was compiled using existing instruments, adjusted for the Ugandan setting and study population. The Index for Inclusion (Booth \& Ainscow, 2002) was used as a guideline to measure the inclusion levels and attitudes of school administrations and teachers. The Ugandan National Accessibility Standards (UNAPD \& Government of Uganda, 2010) were used to assess physical accessibility to schools. To investigate parent child interaction, parental distress, and perceived family relationships, the Parenting Stress Index (Abidin, 1995) was administered and focus group discussions were held with parents. To understand belonging in the family, and the role of the family in care, the Family Relations Test (Bene \& Anthony, 1985; Celestin-Westreich, Baarda \& Ponjaert-Kristoffersen, 1999) was adapted and used in semi-structured interviews with children with spina bifida and their siblings. In addition home visits and observations were conducted. Data was entered and analysed using SPSSI6 and Nvivo version ro.

\section{Findings}

The first research question asked about the knowledge, and attitudes about, and perception of children with spina bifida in Uganda. Most commonly communities believed spina bifida was caused by witchcraft, bad luck, and the use of family planning methods. Communities often assumed the mother did something wrong resulting in this misfortune. Parents would consult traditional healers, biomedical treatment and rehabilitative care. 
Most of them were not supported by family members in accessing care, as family members assumed the child would die and found it a waste of time and resources to invest in the child. Health workers of government health facilities held similar beliefs and were often not informed about the biomedical causes and treatment options. After communities noticed a child survived surgery, and could participate in day to day family life, attitudes changed. The child then gradually became accepted as part of the community, and social life. Whilst this was a common trend, not all parents had this experience; those in the northern region especially struggled with exclusion due to the belief that spina bifida is infectious. The social and cultural change in survival and responses to the survival is recent, and is a complex play of traditional society and cultural values, globalization and access to biomedical care (Bannink, Stroeken, Idro and Van Hove, 2015).

The second research question was set to find out which biomedical health and rehabilitation services children with spina bifida and their parents access, as these closely relate to their survival and daily functioning. Children had poor access to general health services, and difficulties accessing specialized health services for neurosurgery and rehabilitation in our study. The majority could sit unaided; about half could walk unaided. Of those in need of assistive devices, $1 / 3$ did not have this access. The majority of children practiced catheterization and bowel management to manage incontinence. Incontinence management and mobility constraints were described as the most stressful areas in daily functioning (Bannink, Idro, Van Hove, 2016a). The intake of folic acid through supplements and food fortification before and during pregnancy can reduce the incidence of spina bifida. In our study only $8 \%$ of pregnant women took folic acid due to limited education and understanding of women and health workers about the importance of early folic acid intake, late presentation of women at antenatal care, poor supply chains and dilapidated health services (Bannink, Larok, Bauwens, Kirabira \& Van Hove, 2015). Poverty played a major role in the availability and presence of preventative, curative and rehabilitative health services for children with spina bifida in Uganda (Mertens \& Bannink, 2012).

The third research question assessed the factors that promote social inclusion and belonging of children with spina bifida. In our study, children described their households as extended family units. Participation in household activities is a key area in daily life and belonging. In the children's experiences their impairments are restrictive as they prevent them from engaging in daily activities such as fetching water, accessing school, and play, which they see as a missed opportunity to socialize (Bannink, Idro, \& Van Hove, 20I6a). Children with spina bifida had a more negative perception of themselves, were less likely to be in school, had lower cognitive outcomes, and showed less independence in terms of self care compared to their siblings (Bannink, Idro, \& Van Hove, 2016b; Bannink, Idro, \& Van Hove, 20I6e). Children with both spina bifida and hydrocephalus, and with more severe cognitive and motor skills difficulties were more likely to be neglected (Bannink, Idro, \& Van Hove, 2016b). The majority of children, siblings, and parents experienced negative attitudes, verbal abuse, and felt unable to participate in school and community life at some point in time. Higher household income and having support from another adult in taking care of the child improved the child's motor skills and eventu- 
ally schooling and cognitive outcomes (Bannink, Idro, \& van Hove, 2016b). The lack of an enabling environment hindered children from participation, e.g. for those in school, physical accessibility was very limited and classroom participation was affected by lack of space, materials, knowledge and experience of teachers to use diversified teaching methods (Bannink, Idro, \& Van Hove, 20r6c). Inclusive policies to include the children and prevent bullying are in place but lack implementation. In many communities the entire population lived in poverty with limited access to health care, education, water and other services (Bannink, Idro, \& Van Hove, 20r6b).

The fourth research question investigated the role of the family in social inclusion, care, and belonging of children with spina bifida. Given the limited services available, and absence of institutional care, the families are the key care givers and persons to socially relate to in the child's life. In our study, parents had high stress levels with parent child dysfunctional interaction. Mothers were the main caregivers; only a few fathers were involved in child care. Children with spina bifida perceived more negative interaction with their mothers compared to their siblings, but equal positive and dependent interaction (Bannink, Idro, \& Van Hove, 20I6e). Parental stress was mostly explained by the child's inability to walk, incontinence management, and lack of another adult to provide support in caring for the child. Parents in Uganda felt catheterization was disruptive as assisting in catheterization, especially if this involved going to school, interfered with daily work and activities (Bannink, Idro, \& van Hove, 20r6d). Siblings and house-helps played an important role in belonging of children with spina bifida (Bannink, Idro, \& Van Hove, 20I6e). Parents in northern Uganda had less support of house-helps and relatives, and had significantly higher stress scores compared to parents in other regions. Negative cultural beliefs about the impairment and the recent conflict in this region could explain this (Bannink, Stroeken, Idro, \& Van Hove, 2015; Bannink, Idro, \& Van Hove, 2016d). Whilst most parents and families were supportive and keen to include their children, some neglected them (Bannink, Idro, \& Van Hove, 2016a).

\section{Implications for interventions}

Provision of neurosurgery, rehabilitation, and assistive devices are key services which should be provided, and can help remove certain barriers to inclusion. However, cultural attitudes and the strong perception of social able-ism in Uganda, still limit the possibilities of children being included and their ability to access services in their wider communities. We propose strengthening the network at family level, where the environment is more enabling for the children to find a place of belonging and support, and expanding investment and awareness at community and national level.

At the family level, we argue for an extended family centered approach in interventions, in which family support groups include siblings and house-helps, and focus on male involvement. Rather than focusing on individual child rights in terms of autonomy and participation rights, we argue to look at child rights in an interdependent context. 
At community level, awareness raising and advocacy on disability using expert children, youth, and adults to address inclusion is needed to change attitudes and involvement, and enable children with spina bifida and their families to access care and support services at community level. We argue for more investment in community based rehabilitation to improve mobility, and care. In schools, we recommend awareness raising on the cognitive profiles of children with spina bifida and low cost practical inclusive teaching pilots for teachers to enhance participation and inclusion.

At national level, implementation of the Convention of the Rights of Persons with Disabilities and policies to promote inclusion should be followed through and budgeted for. Special attention should be paid to children in the northern region. Mandatory food fortification, sensitization of health workers and women on folic acid intake, and provision of supplies to health facilities are required to prevent neural tube defects. We urge the Ministry of Health to make more efforts towards addressing physical and neuro-disabilities in the general health system, and make budget and staff available to implement low cost but specialized services in collaboration with development agencies. Having embraced the Education for All objectives and Child Protection Guidelines, there is need for the Ministry of Education and Sports, and the Ministry of Gender, Labour and Social Development to critically look at the way children are involved and taught in class, and to take greater steps to ensure bullying is prevented and responded to for all children. Social inclusion and inclusive services need to be integrated in general poverty reduction (Bannink, 20r6).

\section{Implications for further research}

In the future a cohort study following children from birth is recommended to understand mortality, survival, development, and inclusion over time. Longitudinal studies measuring attitudes and practices at different points in time, with exposure to a child with spina bifida and/or hydrocephalus, is the preferred method of studying inclusion in society. We recommend further studies involving women prior to conception, during pregnancy and after birth with frequent measurements of folic acid intake to understand the actual levels of folic acid intake in the population, and evaluation studies to measure possible effects of sensitization campaigns and training of health workers in future. Further biomedical research is necessary on the incidence, causes and treatment of spina bifida and hydrocephalus in low resource settings to provide the most accessible and affordable treatment. Intervention studies in low resource settings could consist of the use of low cost inclusive action plans relevant for large class sizes in schools, and sports in communities and assess their effect on inclusion and belonging. More studies in African countries with a focus on children's perceptions and experiences on social inclusion, care, and belonging are recommended to further develop African Childhood Disability Studies (Chataika \& McKenzie, 2013). We argue for the use of child friendly interview tools, and using a family approach in which childhood is studied from the child's, siblings', parental, and other household members' perspective. In African Childhood Disability Studies, we argue to focus on belonging first - through 'ubuntu' ('I am because 
we are' or 'humanity to others') the person is defined and becomes - before looking at being, and becoming (Bannink, 2016).

\section{References}

Abidin, R.R, (1995). Parenting stress index 3rd edition: Professional manual, Psychological Assessment Resources, Inc, Odessa, TX.

Bangirana, P., Seggane, M., Allebeck, P., Giordani, B., John, C.C., Opoka, O.R., Boivin, M.J. (2009). A preliminary examination of the construct validity of the KABC-II in Ugandan children with a history of cerebral malaria. [Research Support, N.I.H., Extramural Research Support, Non-U.S. Gov't]. Afr Health Sci, 9(3), 186-192.

Bannink, F., Stroeken, K., Idro, R, and Van Hove, G. (2015). Community Knowledge, Beliefs, Attitudes, and Practices Towards Children with Spina Bifida and Hydrocephalus in Uganda. Journal of Disability, Development and Education 62: 2, 182-201, 2015. doi: 10.1080/1034912X.2014.998174.

Bannink, F., Larok, R, Bauwens, L., Kirabira P. and Van Hove, G. (2015). Prevention of spina bifida: folic acid intake during pregnancy in northern Uganda. The Pan African Medical Journal 20: 90. doi: 10.11604/ pamj.2015.20.90.533.

Bannink, F., Idro, R, and Van Hove, G. (2016a). 'I like to play with my friends: children with spina bifida and belonging in Uganda. Social Inclusion, 4 (1). doi: 10.17645/si.v4ir.630.

Bannink, F., Fontaine, J.R.J., Idro, R. and Van Hove, G. (2016b). Cognitive abilities of pre- and primary school children with spina bifida in Uganda. International Journal of Educational Psychology.

Bannink, F., Idro, R. and van Hove, G. (2016c). Teachers' and parents' perspectives on inclusive education for children with spina bifida in Uganda. Journal of Childhood \& Developmental Disorders, 2, 2: 18. doi: $10.4172 / 2472-1786.100026$.

Bannink, F., Idro, R. and Van Hove, G. (2016d). Parental stress and support of parents of children with spina bifida in Uganda. African Journal of Disability, $5(\mathrm{I})$. doi: ro.4102/ajod.v5i1.225.

Bannink, F., Idro, R. and Van Hove, G. (2016e). Family relationships, support and care: perspectives of children with spina bifida in central Uganda. Knowledge Management for Development Journal, Special Issue Knowledge for Disability Inclusive Development II(2): 122-I40.

Bannink, F. (2016). Social inclusion, care and belonging of children with spina bifida: perspectives from Uganda. Ghent: Skribis. ISBN 9789073626409.

Bene, E. and Anthony, J. (1985). Family relations test: children's version: NFER-Nelson Publishing Company Limited.

Beery, K. Buktenica, N.A. and Beery, N.A. (1989). Visual Motor Integration Test (VMI). USA: Pearson Publications.

Booth, T. and Ainscow, M. (2002). Index for Inclusion: developing learning and participation in schools, from http://www.eenet.org.uk/resources/docs/Index\%2oEnglish.pdf

Celestin-Westreich, S., Baarda, B. and Ponjaert-Kristoffersen, I. (1999). Familie Relatie Test: Amsterdam: Pearson Test Publishers.

Chataika, T. and McKenzie, J.A. (2013). Considerations of an African Childhood Disability Studies. In T. a. K.R.C. Curran (Ed.), Disabled Children's Childhood Studies: Critical Approaches in a Global Context (pp. 152-163). Basingstoke: Palgrave.

Curran, T. and Runswick-Cole, K. (2014). Disabled children's childhood studies: a distinct approach? Disability \& Society, 29(10), 1617-1630. doi: 10.1080/09687599.2014.966187

International Federation for Spina Bifida and Hydrocephalus (2014). Spina Bifida - Fact Sheet. [Information Material] Retrieved on October 262015 from http://www.ifglobal.org/images/documents/ IF_SB_factsheet.pdf

Mertens, P. and Bannink, F. (2012). Interdisciplinary care for children with spina bifida in East and Southern Africa. Journal of Medicine and the Person, 10, 3: 129-135. doi: 10.1007s/12682-012-0126x. 
Nampijja, M., Apule, B., Lule, S., Akurut, H., Muhangi, L., Elliott, A.M. and Alcock, K.J. (2010). Adaptation of Western measures of cognition for assessing 5-year-old semi-urban Ugandan children. British Journal of Educational Psychology, 80(1), 15-30. doi: 10.1348/000709909x460600

Northrup, H. and Volcik, K.A. (2000). Spina bifida and other neural tube defects. [Review]. Curr Probl Pediatr, 30(10), 313-332. doi: PMID III47289.

Sparrow, S.S., Balla, D.A., Cicchetti, D. V. and Doll, E. A. (1984). Vineland adaptive behavior scales: interview edition, expanded form manual. Circle Pines, Minn.: American Guidance Service.

Uganda National Action for Physical Disability (UNAPD) \& Government of Uganda (2010). Accessibility Standards: A practical guide to create a barrier-free physical environment in Uganda. Kampala, Uganda: UNAPD.

Verpoorten, C. and Buyse, G.M. (2008). The neurogenic bladder: medical treatment. Pediatr Nephrol, 23(5), 717-725. doi: 10.1007/s00467-007-069I-z.

Warf, B.C., Wright, E.J. and Kulkarni, A.V. (20II). Factors affecting survival of infants with myelomeningocele in southeastern Uganda. J Neurosurg Pediatr, 7(2), 127-133. doi: 10.3171/2010.11.PEDS10428. 